\title{
Effects of single transplantation and multiple transplantation of human umbilical cord mesenchymal stem cells on the recovery of ovarian function in the treatment of premature ovarian failure in mice
}

\section{Xiaodan LV}

Graduate school,Peking Union Medical College Hospital

\section{Chunyi Guan}

National Research Institute for Family Planning

\section{Ying Li}

Graduate School, Peking Union Medical College

\section{Xing Su}

Graduate School, Peking Union Medical College

lu Zhang

National Research Institute for Family Planning

\section{Xueqin Wang}

Graduate School, Peking Union Medical College

Xu Ma

National Research Institute for Family Planning

hongfei Xia ( $\sim$ hongfeixia@126.com )

Reproductive and Genetic Center of National Research Institute for Family Planning https://orcid.org/0000-0003-3305-9108

\section{Research}

Keywords: Premature ovarian failure, hUC-MSCs, Transplantation, Ovarian function

Posted Date: January 20th, 2021

DOI: https://doi.org/10.21203/rs.3.rs-149924/v1

License: (c) (1) This work is licensed under a Creative Commons Attribution 4.0 International License.

Read Full License 


\section{Abstract}

\section{Background}

At present, there is no effective treatment for premature ovarian failure (POF), and stem cell therapy is considered the most promising treatment. Human umbilical cord blood mesenchymal stem cells (hUCMSCs) have shown good regenerative ability in a variety of diseases including POI, but the method and dosage of hUC-MSCs to treat POI are not clear. This study aims to explore the treatment options of hUCMSCs for POF by comparing single injection and multiple injections of hUC-MSCs on the ovarian function repair of POF caused by chemotherapy drugs.

Methods

Female mice were injected intraperitoneally with $30 \mathrm{mg} / \mathrm{kg}$ of busulfan and $120 \mathrm{mg} / \mathrm{kg}$ of cyclophosphamide to induce POF. In the single hUC-MSCs injection group, 7 days after the mice were injected with cyclophosphamide and busulfan, hUC-MSCs were transplanted into these mice. In the multiple injection group, hUC-MSCs were transplanted 7 days, 14 days and 21 days after the mice were injected with cyclophosphamide and busulfan. We evaluated ovarian morphology, fertility, follicle stimulating hormone and estradiol concentration, and follicle count, evaluated POF model and cell transplantation. In addition, real-time PCR, immunohistochemistry, miRNA chip and mRNA chip are used to evaluate the effect of cell therapy.

Results

Compared with the POF group, the ovarian size and primordial follicle count in the hUC-MSC group were significantly improved, and the fertility was also significantly improved. Immunohistochemistry showed that compared with the POF group, the anti-Mullerian hormone and Ki-67 in the ovary of the hUC-MSC group increased significantly, and ovulation was significantly restored. Real-time PCR showed that the expression of follicle stimulating hormone receptor, inhibin and inhibin in the hUC-MSCs group was significantly restored compared with the POF group. The results of mRNA and miRNA chips also showed that hUC-MSC restored ovarian function at the gene level. long-term treatment effect shows that the multiple transplantation hUC-MSCs group is better than the single transplantation hUC-MSCs group. 60 days after the mice were injected with cyclophosphamide and busulfan, the organ coefficient of multiple transplantation of hUC-MSCs increased compared with the POF group, the number of primary follicles increased, and hormone secretion increased.

\section{Conclusion}

The results show that multiple trasplantation of hUC-MSCs can promote the recovery of ovarian function in POF mice more than a single transplantation. This study provides a basis for the therapeutic dose and therapeutic effect of hUC-MSCs on POF. 


\section{Background}

Premature ovarian failure (POF) after chemotherapy is the loss of ovarian function induced by treatment with anticancer drugs. It usually manifests as amenorrhea and infertility, the level of follicle stimulating hormone (FSH) in the serum is increased, and the level of anti-Müllerian hormone (AMH) and serum estrogen is reduced [1]. Anti-cancer therapeutics (such as cyclophosphamide and busulfan) have been shown to be highly damaging to ovarian follicles [2]. Therefore, preservation of fertility and ovarian function should be the main considerations for chemotherapy in women of childbearing age. Recently, stem cells are often used to repair and restore the normal function of injured tissues or organs [3-5], and are also considered as a new option for the treatment of female infertility [6-9].

Although many studies conducted in POF animal models have confirmed that the administration of MSCs obtained from various cell types can protect ovarian function and prove the possibility of restoring ovarian function and structure [10-12]. Among many types of MSCs, umbilical cord-derived MSCs (hUCMSCs) have attracted much attention because of their low immunogenicity and can be used for allogeneic therapy [13]. Moreover, hUC-MSC does not require invasive methods to obtain a sufficient number of cells to make it suitable for regenerative therapy. However, the dose of hUC-MSCs transplantation and the therapeutic effect on POF are still unclear. The purpose of this experiment is to study the therapeutic effect of hUC-MSCs on the ovarian function of POF mice induced by chemotherapy, and to evaluate the repair effect of single and multiple injections of hUC-MSCs on the recovery of ovarian function.

\section{Materials And Methods}

\section{POF mice model}

Six-week-old female Institute of Cancer Research (ICR) mice were purchased from Huayikang Biotechnology Co., Ltd. All animals have free access to food and water. Vaginal smears were used to monitor the estrus cycle. These animals were randomly divided into sham, POI, single transplantation hUC-MSC group and multiple transplantation hUC-MSC group ( $\mathrm{n}=30$ in each group). In order to establish a POI model, mice from the POI, single injection of hUC-MSCs and multiple injections of hUC-MSCs were intraperitoneally injected with a mixture of $120 \mathrm{mg} / \mathrm{kg}$ cyclophosphamide and $30 \mathrm{mg} / \mathrm{kg}$ busulfan. The sham group was injected with saline only. The day of receiving chemotherapy drugs was recorded as the first day. Vaginal smear test to observe the estrus cycle. On the 7th day after chemotherapy, mice in the single injection of hUC-MSCs and multiple injections of hUC-MSC were injected with $100 \mu$ of $2 \times 10^{6}$ hUCMSCs cell suspension into the tail vein [14]. And on the 14th and 21st days after chemotherapy, mice in the hUC-MSCs group injected multiple times were injected with $100 \mu \mathrm{l}$ of $2 \times 10^{6}$ hUC-MSCs cell suspension. In the fertility testing experiment, we used mice in the sham group, POI, single injection of hUC-MSCs and multiple injections of hUC-MSCs 14 days and 60 days after chemotherapy $(n=5$ in each group), and caged according to the ratio of male to female 2:1. All procedures have been approved by the Animal Protection and Use Committee of the National Family Planning Society of China. This study was 
conducted in strict accordance with the recommendations in the "Guidelines for the Care and Use of Laboratory Animals of the National Institutes of Health".

\section{Isolation and culture of hUC-MSCs}

Human umbilical cord samples were obtained from full-term babies delivered by caesarean section in Haidian Maternal and Child Health Hospital, and the umbilical cord was washed with PBS to remove contaminated blood. Remove the umbilical cord to remove the arteries and veins, cut them into small pieces of 0.5-1 $\mathrm{mm}^{3}$, and place them in the bottom of the tissue culture dish. Place the petri dish in a $37^{\circ} \mathrm{C}, 5 \% \mathrm{CO}_{2}$ incubator. Cells are cultured in MEM-Alpha complete medium ( $10 \%$ fetal bovine serum, $1 \%$ diabody). When the cells reach about $90 \%$ confluence, they are digested with $0.25 \%$ trypsin, and the $1: 2$ separation and passage are continued. And make the cells grow to the logarithmic growth phase $[15,16]$.

\section{Immunophenotypic analysis}

Human MSC Analysis Kit (BD, NJ, USA) is used to identify MSC. Cells are resuspended in $1 \times 10^{7} \mathrm{cell} / \mathrm{s} / \mathrm{ml}$ buffer, $100 \mu$ of prepared cell suspension was added to 9 tubes and incubated with various fluorescent dye-conjugated specific antibodies (FITC Mouse Anti-Human CD90 (tube 1); PE Mouse Anti-Human CD44 (tube 2); PerCP-Cy ${ }^{\text {TM }} 5.5$ Mouse Anti-Human CD105 (tube 3); APC Mouse Anti-Human CD73 (tube 4); Nothing (tube 5); hMSC Positive Isotype Control Cocktail and PE hMSC Negative Isotype Control Cocktail (tube 6,8); hMSC Positive Cocktail and PE hMSC Negative Cocktail (tube 7,9) in the dark for 30 min at room temperature. The results were analyzed by flow cytometry, and the experimental results were verified three times.

\section{Osteogenic Differentiation}

To promote osteogenic differentiation, the cells were seeded into twelve-chamber-slides and cultured in Dulbecco's modified Eagle's medium (DMEM; HyClone, Utah, USA) containing $10 \%$ fetal bovine serum (FBS). When the cells reached $70 \%-80 \%$ confluence, replaced osteogenic differentiation medium (HyClone, Utah, USA) and changed every 3 days [17]. Two weeks later, the calcified extracellular matrix was stained with $2 \%$ Alizarin Red to confirm osteogenic differentiation. The experiment was repeated three times.

\section{Adipogenic Differentiation}

To induce adipogenic differentiation, cells were cultured in MSCs medium until reaching $90 \%$ confluence. Then, the cells were induced in adipogenic induction medium (MEM Alpha Modification (HyClone, Utah, USA) for 3 days. After 3 days, adipogenic induction mediumwas replaced by maintenance medium containing sorely of $10 \mu \mathrm{M}$ insulin and MSCs medium and changed every 3 days. For the negative control, the cells were cultured in MSCs medium [18]. After 1 week, formation of intracellular lipid droplets was stained by Oil Red $O$ staining. The experiment was repeated three times.

\section{ELISA detection of mice estradiol (E2) and follicle-stimulating hormone (FSH)}


In order to ensure that each group of mice estrus were in the same period, mice were administered by intraperitoneal injection of Pregnant Mare Serum Gonadotropin (PMSG) 2 days before euthanasia. Blood samples were collected on the $14,21,28$, and 60 days after the POF mold. The samples were incubated overnight at $4^{\circ} \mathrm{C}$, then were centrifuged for $5 \mathrm{~min}$ at $4000 \mathrm{rpm}$. The resulting supernatant sera were collected. The levels of $E_{2}$ and $F S H$ were respectively measured by Mouse $E_{2}$ ELISA Kit (Bio-Swamp, Wuhan, China) and Mouse FSH ELISA Kit (Bio-Swamp, Wuhan, China). The experiment was repeated three times.

\section{Histologic staining and follicle counting}

The ovaries were fixed overnight in $4 \%$ paraformaldehyde, embedded in paraffin by dehydration, and serial sectioning was adopted. The thickness of the serial sections was $5 \mu \mathrm{m}$, and every ten sections were counted. 20 sections were taken and stained with hematoxylin and eosin (H\&E). The ovarian primordial follicles, primary follicles, secondary follicles and mature follicles were counted under TE2000-u reverse phase microscope (Nikon, Tokyo, Japan). The classification and characteristics of all levels of follicles are determined as follows: primitive follicle is close to the white membrane, and the oocyte is surrounded by a single layer of flat granular cells; primary growth follicle is surrounded by one or more layers of cubic granular cells, and red staining appears between the two zona pellucida, the follicular membrane of connective tissue appears on the periphery of the follicle; follicular cavity appears in the secondary growth follicle, and the follicular membrane can be separated into the inner and outer membranes; mature follicle has obvious cumulus, large follicular cavity, and many capillaries between the cells; Atresia follicle follicle wall collapses, egg cell structure is not clear, or even disappear, zona pellucida shrinks.

\section{Immunohistochemical analysis}

The paraffin sections were deparaffinized, rehydrated and high pressured in a citrate buffer $(\mathrm{pH} 6.0)$ for $2 \mathrm{~min}$ to retrieve antigenicity. Then, the samples were incubated with $3 \%$ hydrogen peroxide $10 \mathrm{~min}$ to quench endogenous peroxidase activity. Sections were blocked non-specific antigen with $10 \%$ goat serum. After that, sections were incubated with Anti-Ki67 antibody (1:100; Abcam, Cambridge, UK) or mouse anti-human anti-Müllerian hormone (AMH, 1:30; AbD Serotec, Oxford, UK) in a humidified chamber overnight at $4^{\circ} \mathrm{C}$. Negative control were conducted with $10 \%$ goat serum overnight at $4^{\circ} \mathrm{C}$ alone. After incubating with primary antibody, peroxidase-conjugated affinipure goat-anti-rabbit IgG (1:200; ZSBIO, Beijing, China) or peroxidase-conjugated affinipure goat-anti-mouse IgG (1:200; ZSBIO, Beijing, China) were added for 1 hour at room temperature. Then, colourated with 3, 3-diaminobenzidin (DAB; ZSBIO, China) at room temperature without light for $10 \mathrm{~min}$ and counterstained with hematoxylin for $10 \mathrm{~s}$. After sealing slides, the samples were photographed with microscope (Nikon, Tokyo, Japan). The experiment was repeated three times.

\section{Immunofluorescence staining}


Ovary samples were collected and fixed in $4 \%$ paraformaldehyde overnight at $4^{\circ} \mathrm{C}$, then, dehydrated with $30 \%$ sucrose 1 week. After that, samples were fixed with the Tissue-Tek OCT Compound (Sakura Finetek Middle East, Dubai, United Arab Emirates) at $-80^{\circ} \mathrm{C}$ and sliced in 7 um thick sections at $-25^{\circ} \mathrm{C}$. Slides were blocked with $10 \%$ goat serum for 1 hour at room temperature. Slides were then incubated with mouse anti-human nuclei monoclonal antibody (1:100; Millipore, USA) at $4^{\circ} \mathrm{C}$ overnight. $10 \%$ goat serum as the primary antibody were used as negative controls. Sections were probed with TRITC-labeled IgG (1:200; ZSBIO, Beijing, China) and counterstained with 4', 6-diamidino-2-phenylindol (DAPI). Fluorescence images were taken through a fluorescence microscope (DMI3000; Leica, Heidelberg, Germany). The experiment was repeated three times.

\section{Microarray hybridization and data analysis}

According to the manufacturer's instructions, the miRNAeasy Mini Kit (Qiagen GmbH, Hilden, Germany) was used to isolate total RNA from the ovaries of three mice in the control, POF and hUC-MSCS groups, respectively. The miRNA microarray including probe labeling, hybridization, hybridization image scanning and initial data analysis was performed by LC Sciences (LC Sciences, Houston, Texas, USA). Use LCmiRHumanMouseRat_11.0_080411 array. The mRNA chip uses the OneArray chip (Tecenet, Chengdu, China). Use cyclic local weighted regression (LOWESS) method for normalization. $t$ test was performed between the control group and the POF group, the POF group and the hUC-MSCs group, and the hUCMSCs group and the control group, and the statistical analysis of the microarray data has been performed.

\section{Quantitative reverse-transcriptase polymerase chain reaction (qRT-PCR)}

The Trizol (Invitrogen, CA, USA) method is used to extract RNA from ovarian tissue. The RNA was extracted with reverse transcription kit (TakaRa Biotechnology, Shanghai, China) reverse transcribed CDNA for qRT-RNA detection. The experiment was repeated at least 3 times less, and $P<0.05$ was considered statistically significant. Primer sequence: mRNA-FSHR-Forward, 5'GAGGTGCAAGCCCAGATTTA-3'; mRNA-FSHR-Reverse, 5'-GAGGGACAAGCACGTAACTATT-3'; mRNAINHIBINa-Forward, 5'-TCTGAACCAGAGGAGGAAGAT-3'; mRNA-INHIBINa-Reverse, 5'-

GGGATGGCCGGAATACATAAG-3'; mRNA-INHIBINß-Forward, 5'-AAGAAAGAGGTGGATGGAGATG-3'; mRNAINHIBINß-Reverse, 5'-CAGCATGAGGAAAGGTCTATGT-3'; mRNA-GAPDH-Forward, 5'GGTGAAGGTCGGTGTGAACG-3'; mRNA-GAPDH- Reverse, 5'-CTCGCTCCTGGAAGATGGTG-3'

\section{Statistical analysis}

To determine significance between two groups, the unpaired Student's t test was used. One-way ANOVA was used to calculate the significant differences among the groups. Prism6.0 software was used to paint. $P$ value less than 0.05 was considered to be significant.

\section{Results}




\section{Identification and characterization of hUC-MSCs}

hUC-MSCs have a spindle-shaped morphology and successfully differentiated into bone (Fig. 1a and b) and adipogenic (Fig. 1c and d). Flow cytometry is used to identify the expression profile of surface markers. hUC-MSC is negative for CD11b, CD19, CD34, CD45 and HLA-DR, while CD29, CD73, CD90 and CD105 are positively expressed as surface markers of MSC (Fig.1e).

To detect the graft and differentiation of the hUC-MSCs in vivo, the expression of human nuclei antigen was evaluated by Immunofluorescence staining. As shown in Fig. 1f, the human umbilical cord mesenchymal stem cells injected through the tail vein of mice were injected 7 days later. It still survives in the body and migrates to the injured site. It can be seen that the hUC-MSCs displayed by red fluorescence are mainly distributed in the follicular granulosa cells of the hUC-MSCs treatment group, which shows that hUC-MSCs can survive in mice and migrate to the injured site to play a repair role.

\section{Effects of hUC-MSCs transplantation on the appearance and fertility of ovaries in POF mice}

The therapeutic effect of hUC-MSCs on POF was evaluated by ovarian organ coefficient. Compared with the POF group, the ovaries of mice in the single injection of hUC-MSCs treatment group had a significant increase in organ coefficient on the 14th day $(P<0.01$, Figure 2a-e). In the multiple injections of hUC-MSCs group, compared with POF group, the organ coefficient of mouse ovary increased significantly on the 28th and 60th day $(P<0.05$, Fig. $2 \mathrm{f}-\mathrm{h})$. It showed that the appearance of the ovaries after repeated injections of hUC-MSCs was significantly restored and the treatment effect was maintained for a long time. The fertility test of mice showed that both single injection and multiple injection groups of hUCMSCs can significantly restore the fertility of POF mice in the short-term (Fig 2i) and long-term (Fig 2j) $(P<0.05)$. The results show that hUC-MSCs can significantly restore the ovarian function of POF mice.

\section{The transplantation of hUC-MSCs restored the ovarian reserve and cell proliferation of POF mice}

$\mathrm{AMH}$ is a member of the transforming growth factor- $\beta$ (TGF $\beta$ ) family and expressed by granulosa cells. $\mathrm{AMH}$ levels are significantly correlated with the reserve capacity of ovary. The results are shown in figure 3. Compared with the control group, the POF group hardly expressed $\mathrm{AMH}$, while in the single injection of hUC-MSCs group and multiple injections of hUC-MSCs group, we observed an increase in AMH expression (Fig $3 \mathrm{a}$ and $\mathrm{b}$ ). Ki67 is a DNA binding protein that is expressed in all active cell cycle stages and can be used as a marker antigen for cell proliferation. The immunohistochemical test results are shown in figure 4. Compared with the control group, the follicles of POF mice are almost negative and the proliferative phase is rare. In the single injection of hUC-MSCs group, the mouse follicles are lightly stained, indicating that the cell proliferation potential is restored (Fig 4a). In the group of multiple injections of hUC-MSCs, deep staining of mouse follicles was observed on day 60 (Fig 4b), showing a good therapeutic effect.

\section{Restoration of ovarian structure and follicular development through hUC-MSCs transplantation}


Observe the structure of the ovary by H\&E staining (Fig. 5a and f). In the sham group, well-developed primordial follicles, primary follicles, secondary follicles and mature follicles can be observed. In the POF mouse model, the ovaries of mice are atrophy, the number of follicles at each stage decreases, and the atretic follicles increase. In the single injection of hUC-MSCs group, the number of mature follicles increased significantly compared with the POF group, and the number of follicles at various levels also recovered significantly $(P<0.05$, Fig.5b-e). In the group of multiple injections of hUC-MSCs, the number of primordial follicles and the number of primary follicles increased significantly $(P<0.05$, Fig. $5 \mathrm{~g}$ and $\mathrm{h})$. The results show that hUC-MSCs have a good therapeutic effect on follicle recovery.

\section{hUC-MSCs transplantation restored hormone levels}

The levels of $E_{2}$ and FSH in mouse serum were detected by ELISA, and the results are shown in figure 6 . Compared with mice in the POF group, the $\mathrm{E}_{2}$ content in the serum of mice in the single hUC-MSCs treatment group increased significantly on the 21st, 28th, and 60th day $(P<0.05$, Fig.6a), and the FSH content was significantly reduced on the 60th day $(P<0.05$, Fig.6b). Compared with mice in the POF group, mice in the multiple hUC-MSCs treatment group had a significant increase in serum $\mathrm{E}_{2}$ content on the 28th and 60th day $(P<0.05$, Fig.6c), and the FSH content on the 28th and 60th day The daily average decreased significantly $(P<0.05$, Fig.6d). The results showed that the therapeutic effect of multiple injections of hUC-MSCs was significantly better than single injection.

\section{Changes of gene expression in the ovaries of POF mice treated with hUC-MSCs}

We selected the genes FSHR, INHIBINa, and INHIBIN $\beta$ that mainly exist in the granulosa cells of follicles, and detected the changes in gene expression by QRT-PCR. The results are shown in figure 7. Compared with the POF group, the expression of FSHR in the single injection of hUC-MSCs group and multiple injections of hUC-MSCs group recovered on 14 days, 21 days, 28 days and 60 days (Fig.7 a and b). The expression level of INHIBINa in the single injection hUC-MSCs group at 28 days and the multiple injection hUC-MSCs group at 60 days was significantly higher than that in the POF group (Fig7.c and d). The expression level of INHIBIN $\beta$ in the single injection hUC-MSCs group at 28 days and 60 days, and the multiple injection hUC-MSCs group at 60 days was significantly higher than that in the POF group (Fig7. e and $\mathrm{f}$ ). The results showed that the granulosa cell-related genes in the follicles of POF mice treated with hUC-MSCs were restored.Volcano map is a common method to observe differentially expressed genes between two groups. It can visually see the relationship between genes change multiples and difference significance. Figure 8a shows the miRNA chip volcanograph analysis of POF and hUC-MSCs treatment group, sham group and hUC-MSCs and POF and sham group. Figure $8 \mathrm{~b}$ shows the volcano map analysis of the mRNA chip. Among them, green is a down-regulated gene, and red is an up-regulated gene. We can observe that the miRNA chip shows that there are fewer differential genes between the normal group and the hUC-MSCs treatment group. This indicates that hUC-MSCs repaired POF damage induced by chemotherapy drugs at the gene level.

\section{Discussion}


The incidence of POF in women accounts for 1\% [19], and CXT treatment is one of the causes of POF [20]. Therefore, treating ovarian degenerative changes and restoring ovarian function is the key to ensuring female reproductive health [21]. Although based on a large amount of data on the feasibility of stem cells to treat various degenerative diseases, however, due to the differences between animal models and the physical differences between model animals and humans, the therapeutic effects of stem cells are still controversial [22].

Umbilical cord mesenchymal stem cells were considered to be more effective for cellular therapy [23]. The hUC-MSCs have been shown to exhibit high differentiation potential and high proliferative activity. Moreover, hUC-MSCs express the stem cell marker CD44, CD73, CD90 and CD105 [24-26] and have the potential to differentiate into cells of all three embryonic tissue layers [27-29]. In our present study, hUCMSCs had differentiated into adipocytes and bone cells. Hormonal imbalance with a low concentration of $\mathrm{E}_{2}$ and a high concentration of FSH in serum is a typical symptom of POF [30]. Therefore, the improvement of the female sex hormonal levels is an important indicator of the restoration of ovarian function. In our study, the hormone levels of the POF mice were restored, which indicate the hUC-MSCs improved ovarian endocrine function of the chemotherapy drug damage.

In the fertility test, we found that the fertility of POF mice treated with hUC-MSCs was significantly restored on the 14th and 60th days. The results show that hUC-MSCs has long-term treatment for the ovaries of POF mice and can significantly restore the fertility of the ovaries. To confirm the hUC-MSCs could improve the ovarian function, we also studied the organ coefficient of ovary and the number of follicles. In the multiple intravenous group, the organ coefficient of ovary significantly rosein the treat group compared with that in the POF group. After the hUC-MSCs transplantation, all stages of follicles in MSCs group rose compared with that in the POF group. Secreted by the follicular granulosa cells, AMH is one of the best indicators reflecting the ovarian reserve [31]. Immunohistochemical results showed that $\mathrm{AMH}$ expressed in the treatment group mouse ovarian tissue, and most of $\mathrm{AMH}$ expression is in granulosa cells of the mature follicles. The results showed that hUC-MSCs restored the follicular storage function of the ovaries of POF mice.

To confirm the hUC-MSCs could promote the ovarian granulosa cells regeneration to improve ovarian function in mice. Ki67 is the key factor of the ribosome synthesis in cell division, which is necessary for cell proliferation [32]. Ki67 positive expression indicated the hUC-MSCs could restore granulosa cell proliferation to maintain the normal function of the ovarian follicles. Mesenchymal stem cells were detected in follicular granulosa cells with tracing the ovarian tissue freezing slice, which show the hUCMSCs could selectively migrate and stay in damaged tissues. This result may be associated with inflammatory effect [33].

To further verify the effect of hUC-MSCs on the restoration of ovarian function at the gene level, we used qRT-PCR to detect the expression of FSHR, INHIBINa and INHIBIN $\beta$. The results showed that the expression of hUC-MSCs treatment group was higher than that of POF group, which showed that under hUC-MSCs treatment, ovarian granulosa cell secretion and FSH secretion increased, and ovarian function 
was restored. In the miRNA chip analysis, we found that compared with the control group, most miRNAs recovered after hU-MSCs treatment, indicating that hU-MSCs has a better therapeutic effect.To sum up, hUC-MSCs transplantation can treat chemotherapy drugs cause POF, organ coefficient and hormone levels recovery effect in multiple transplantation mice were superior to single transplantation mice. However, more investigations are needed to confirm the mechanism involved in recovery of ovarian function.

\section{Declarations}

\section{Ethics approval and consent to participate}

The animal-related experiments, including the isolation of human umbilical cord mesenchymal stem cells and the mouse premature ovarian failure modeling, were approved by the China of National Research Institute for Family Planning (Ethics Number 2015-16). All applicable institutional and national guidelines for the care and use of animals were followed.

\section{Consent for publication}

All authors gave consent for publication.

\section{Availability of data and materials}

The datasets during and/or analysed during the current study available from the corresponding author on reasonable request.

\section{Competing interests}

The authors declare that they have no competing interests.

\section{Funding}

This work was funded by grants from CAMS Innovation Fund for Medical Sciences (CIFMS, 2018-I2M-1004) and National Natural Science Foundation of China (No.81771590) and National Research Institute for Family Planning (No. 2020GJZ02).

\section{Authors' contributions}

Xiaodan Lv and Lu Zhang performed animal experiments and data processing, Chunyi Guan wrote the manuscript, Ying Li performed histological analysis, Xueqin Wang and Xing Su performed molecular experiments, and Xu Ma and Hongfei Xia provided funding and experimental guidance.

\section{Acknowledgements}

The authors thank for Dr. Shi Tian for experimental technical support. 


\section{References}

1. Rudnicka E, Kruszewska J, Klicka K, et al. Premature ovarian insufficiency - aetiopathology, epidemiology, and diagnostic evaluation. Prz Menopauzalny. 2018;17(3):105-108.

2. Jankowska K. Premature ovarian failure. Prz Menopauzalny. 2017;16(2):51-56.

3. Jin MC, Medress ZA, Azad TD, Doulames VM, Veeravagu A. Stem cell therapies for acute spinal cord injury in humans: a review. Neurosurg Focus. 2019;4 6(3): E10.

4. Casiraghi F, Remuzzi G. Mesenchymal stromal cells in kidney transplantation. Curr Opin Nephrol Hypertens. 2019; 28(1):40-46.

5. Bartczak A, McGilvray I, Keating A. Mesenchymal stromal cell therapy to promote cardiac tissue regeneration and repair. Curr Opin Organ Transplant. 2017; 22(1):86-96.

6. Esfandyari S, Chugh RM, Park HS, Hobeika E, Ulin M, Al-Hendy A. Mesenchymal Stem Cells as a Bio Organ for Treatment of Female Infertility. Cells. 2020; 9(10):2253.

7. Wang J, Ju B, Pan C, Gu Y, Zhang Y, Sun L, Zhang B, Zhang Y. Application of Bone Marrow-Derived Mesenchymal Stem Cells in the Treatment of Intrauterine Adhesions in Rats. Cell Physiol Biochem. 2016;39(4):1553-1560.

8. Abomaray F, Gidlöf S, Bezubik B, Engman M, Götherström C. Mesenchymal Stromal Cells Support Endometriotic Stromal Cells In Vivo. Stem Cells Int. 2018; 2018:7318513.

9. Xie Q, Xiong X, Xiao N, He K, Chen M, Peng J, Su X, Mei H, Dai Y, Wei D, Lin G, Cheng L. Mesenchymal Stem Cells Alleviate DHEA-Induced Polycystic Ovary Syndrome (PCOS) by Inhibiting Inflammation in Mice. Stem Cells Int. 2019; 2019:9782373.

10. Manshadi MD, Navid S, Hoshino Y, Daneshi E, Noory P, Abbasi M. The effects of human menstrual blood stem cells-derived granulosa cells on ovarian follicle formation in a rat model of premature ovarian failure. Microsc Res Tech. 2019; 82(6):635-642.

11. Terraciano P, Garcez T, Ayres L, Durli I, Baggio M, Kuhl CP, Laurino C, Passos E, Paz AH, Cirne-Lima E. Cell therapy for chemically induced ovarian failure in mice. Stem Cells Int. 2014; 2014:720753.

12. Yang M, Lin L, Sha C, Li T, Zhao D, Wei H, Chen Q, Liu Y, Chen X, Xu W, Li Y, Zhu X. Bone marrow mesenchymal stem cell-derived exosomal miR-144-5p improves rat ovarian function after chemotherapy-induced ovarian failure by targeting PTEN. Lab Invest. 2020 Mar;100(3):342-352.

13. Nagamura-Inoue T, He H. Umbilical cord-derived mesenchymal stem cells: Their advantages and potential clinical utility. World J Stem Cells. 2014; 6(2):195-202.

14. Lai D, Wang F, Chen Y, Wang L, Wang Y, Cheng W. Human amniotic fluid stem cells have a potential to recover ovarian function in mice with chemotherapy-induced sterility. BMC Dev Biol. 2013; 13(1):113.

15. Yang $\mathrm{H}$, Yang $\mathrm{H}$, Xie Z, Wei L, Bi J. Systemic transplantation of human umbilical cord derived mesenchymal stem cells-educated T regulatory cells improved the impaired cognition in AßPPswe/PS1dE9 transgenic mice. PLoS One. 2013; 8(7): e69129. 
16. Yang H, Sun J, Li Y, Duan WM, Bi J, Qu T. Human umbilical cord-derived mesenchymal stem cells suppress proliferation of PHA-activated lymphocytes in vivo by inducing CD $4^{+} \mathrm{CD} 25^{\text {high }} \mathrm{CD} 45 \mathrm{RA}{ }^{+}$ regulatory T cell production and modulating cytokine secretion. Cell Immunol. 2016; 302:26-31.

17. Kern S, Eichler H, Stoeve J, Klüter H, Bieback K. Comparative analysis of mesenchymal stem cells from bone marrow, umbilical cord blood, or adipose tissue. Stem Cells. 2006 ;24(5):1294-301.

18. Savickiene J, Treigyte G, Baronaite S, Valiuliene G, Kaupinis A, Valius M, et al. Human Amniotic Fluid Mesenchymal Stem Cells from Second- and Third-Trimester Amniocentesis: Differentiation Potential, Molecular Signature, and Proteome Analysis. Stem Cells Int. 2015:319238.

19. Meczekalski B, Maciejewska-Jeske M, Podfigurna A. Reproduction in premature ovarian insufficiency patients - from latest studies to therapeutic approach. Prz Menopauzalny. 2018;17(3):117-119.

20. Na, J., Kim, G.J. Recent trends in stem cell therapy for premature ovarian insufficiency and its therapeutic potential: a review. J Ovarian Res 2020;13(1):74.

21. Ghahremani-Nasab M, Ghanbari E, Jahanbani Y, Mehdizadeh A, Yousefı M. Premature ovarian failure and tissue engineering. J Cell Physiol. 2020; 235(5):4217-4226.

22. Mohamed SA, Shalaby SM, Abdelaziz M, et al. Human Mesenchymal Stem Cells Partially Reverse Infertility in Chemotherapy-Induced Ovarian Failure. Reprod Sci. 2018;25(1):51-63.

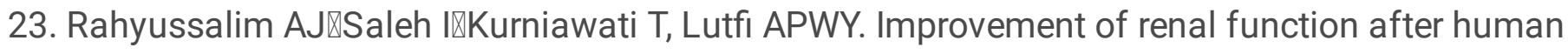
umbilical cord mesenchymal stem cell treatment on chronic renal failure and thoracic spinal cord entrapment: a case report. Journal of Medical Case Reports. 2017; 11(1):334.

24. Muñiz C, Teodosio C, Mayado A. Ex vivo identification and characterization of a population of $\mathrm{CD} 13^{\text {high }} \mathrm{CD} 105^{+} \mathrm{CD} 45^{-}$mesenchymal stem cells in human bone marrow. Stem Cell Research \& Therapy. 2015; 6(1):169.

25. Ramos TL, Sánchez-Abarca LI, Muntión S. MSC surface markers (CD44, CD73, and CD90) can identify human MSC-derived extracellular vesicles by conventional flow cytometry. Cell Communication \& Signaling Ccs. 2016;14:2.

26. Ghaneialvar H, Soltani L , Rahmani HR. Characterization and Classification of Mesenchymal Stem Cells in Several Species Using Surface Markers for Cell Therapy Purposes. Ind J Clin Biochem. 2018; 33(1):46-52.

27. Kim J, Lee Y, Kim H, Hwang KJ, Kwon HC, Kim SK, et al. Human amniotic fluid-derived stem cells have characteristics of multipotent stem cells. Cell Prolif. 2007; 40:75-90.

28. Rentsch C, Hess R, Rentsch B, Hofmann A, Manthey S, Scharnweber D, et al. Ovine bone marrow mesenchymal stem cells: isolation and characterization of the cells and their osteogenic differentiation potential on embroidered and surface-modified polycaprolactone-co-lactide scaffolds. In Vivo Cell. Dev.Biol.-Animal. 2010; 46:624-634.

29. Tsai MS, Hwang SM, Tsai YL, Cheng FC, Lee JL, Chang YJ. Clonal amniotic fluid-derived stem cells express characteristics of both mesenchymal and neural stem cells. Biol Reprod. 2006; 74:545-551.

30. Torrealday S, Pal L. Premature menopause. Endocrinol Metab Clin North Am. 2015; 44:543-557. 
31. Seifer DB, MacLaughlin DT, Christian BP. Early follicular serum müllerian-inhibiting substance levels are associated with ovarian response during assisted reproductive technology cycles. Fertil Steril. 2002; 77 (3):468-471.

32. MacCallum DE, Hall PA. The location of pKi67 in the outer dense fibrillary compartment of the nucleolus points to a role in ribosome biogenesis during the cell division cycle.J Pathol. 2000;190(5):537-544.

33. Ley K, Laudanna C, Cybulsky MI. Getting to the site of inflammation: The leukocyte adhesion cascade updated. Nat Rev Immunol. 2007;7: 678-689.

\section{Figures}




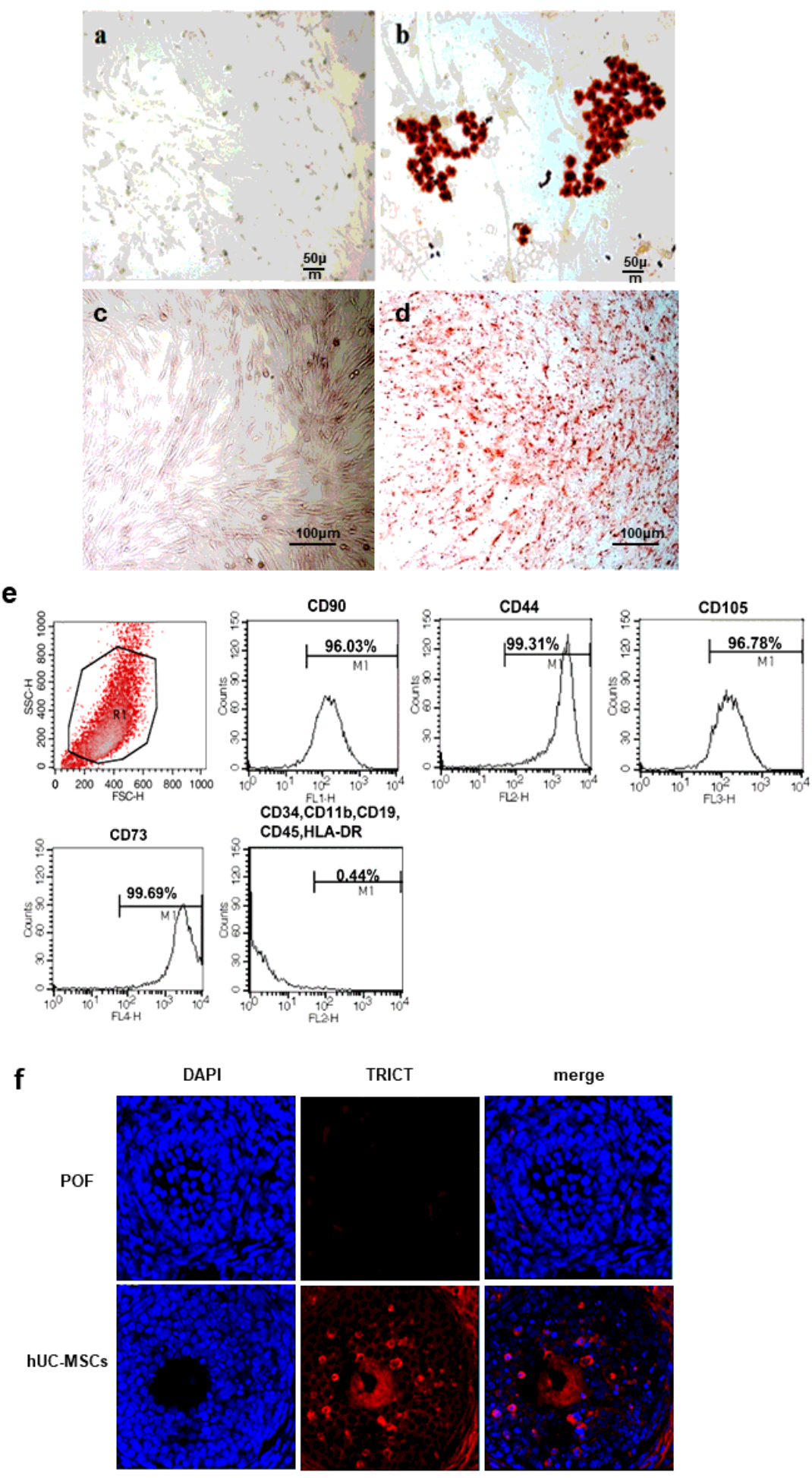

\section{Figure 1}

The characterization and differentiation of hUC-MSCs. (a, b) The hUC-MSCs differentiate into osteoblasts, scale bar $=50 \mu \mathrm{m} . \mathrm{n}=3$. (c, d) adipocytes, scale bar $=100 \mu \mathrm{m} . \mathrm{n}=3$. (e) Flow cytometric analysis of hUCMSCs. CD44, CD73, CD90, and CD105 were positive and CD34, CD11b, CD19, CD45 and HLA-DR were negative. $n=3$. (f) Human nuclei antigen was negative in POF murine ovarian section, the recipient ovaries after hUC-MSCs transplantation were expressed human nuclei antigen. $\mathrm{n}=5$. 


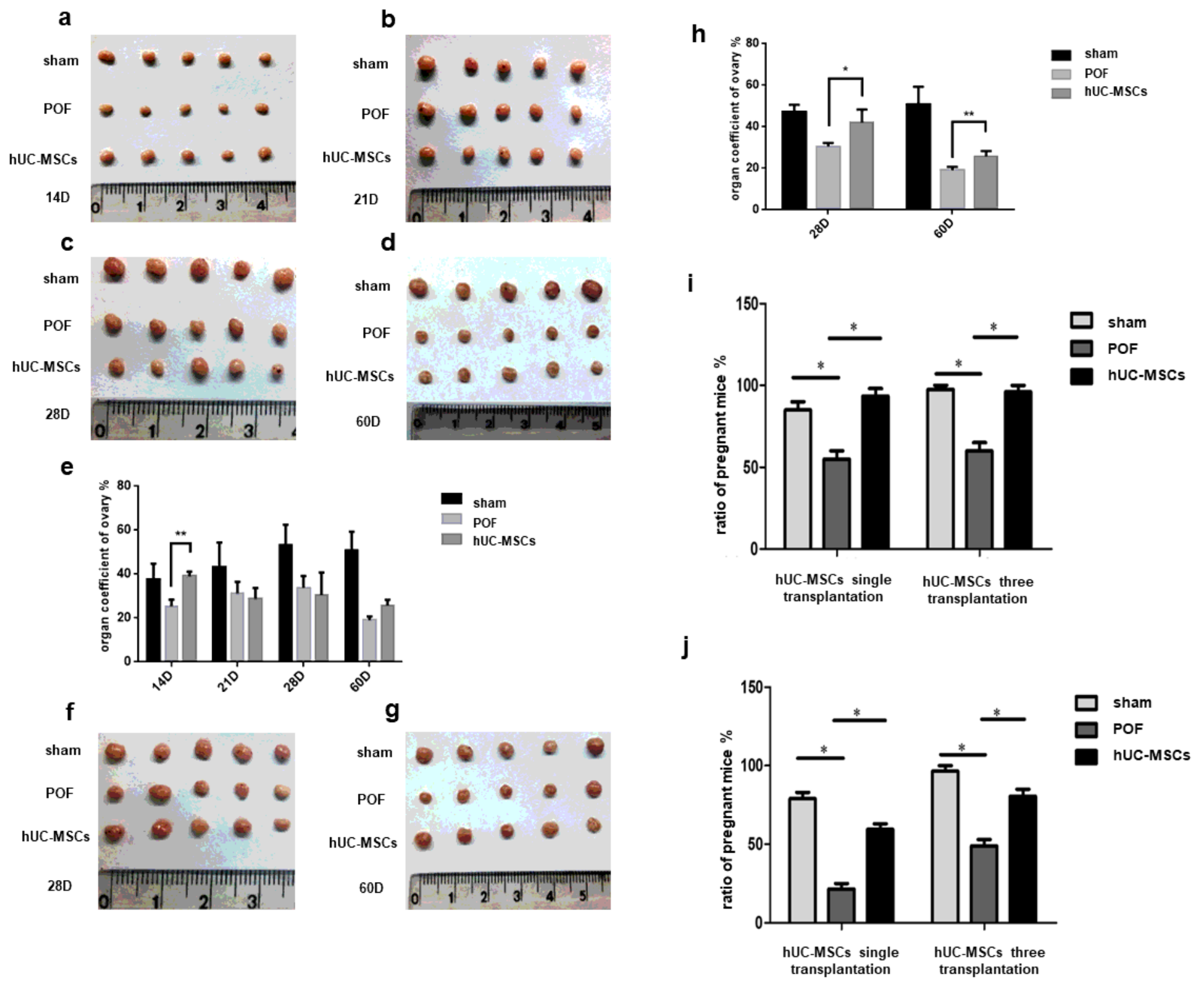

Figure 2

Changes of ovary weight in the once intravenous group and the multiple intravenous group over 60 days. $(a, b, c, d)$ In the once intravenous group, ovarian volume of mice were remarkably increased at $7,14,21$, 28 days post-induction, respectively. $n=5$. $(f, g)$ The multiple intravenous group showed significantly increased of ovarian volume at 28,60 days post-induction, respectively. $n=5$. $(e, h)$ The histogram represents the results of statistical analysis of ovarian weight by single and multiple injections, respectively. Organ coefficient $=$ organ weight/weight, $n=5$. (i) Fertility of single hUC-MSCs injection on the 14th day and three hUC-MSCs injection on the 28th day. $n=5$. (j) Changes in mouse fertility 60 days after POI modeling. $n=5$. * $P<0.05 ;{ }^{*} \mathrm{P}<0.01$. 


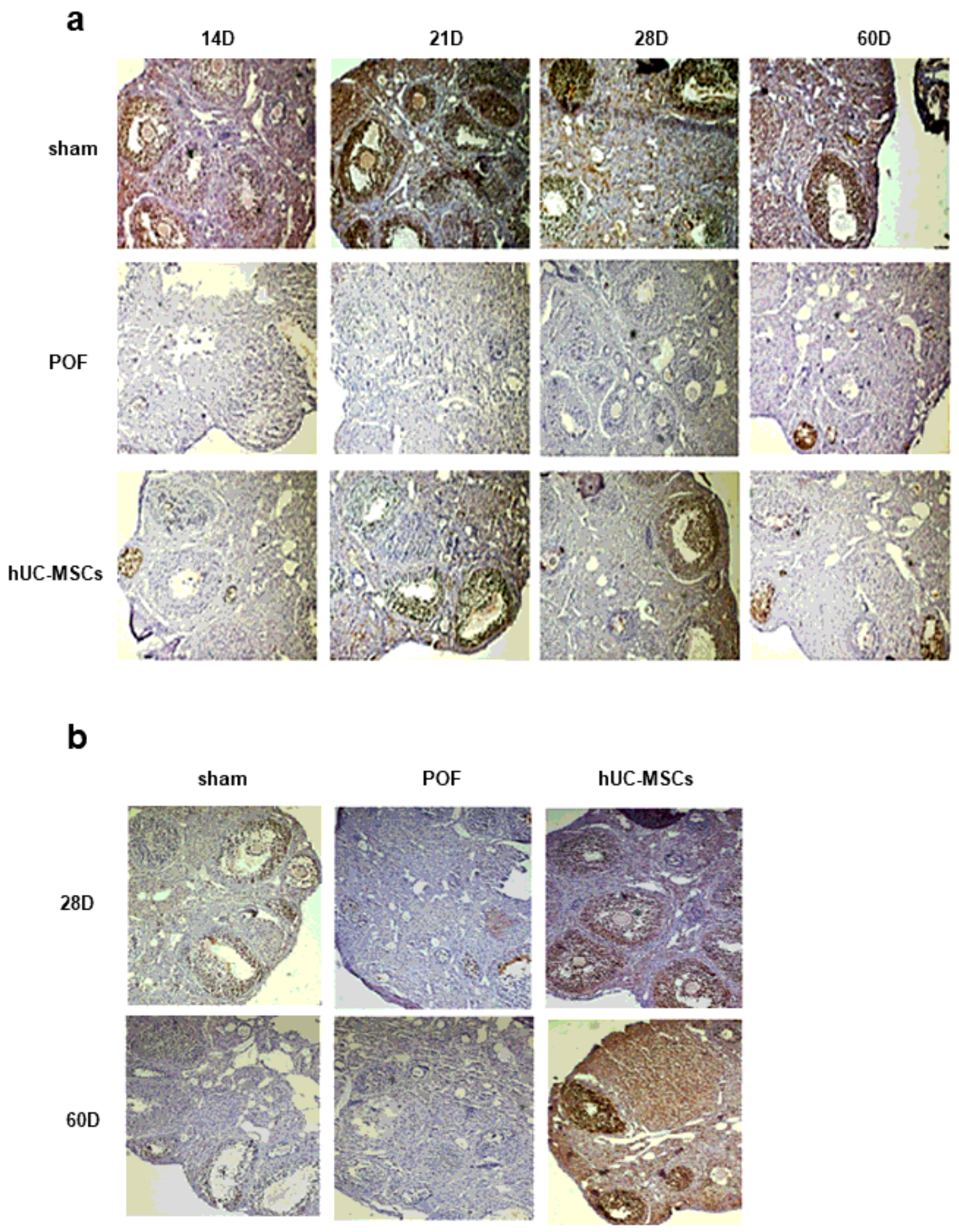

Figure 3

The ovarian reserve capacity analysis. Immunohistochemistry for AMH in once intravenous group (a) and the multiple intravenous group (b). Strong expression of AMH were seen in Sham group at each time point, granulosa cells were negative in POF group, AMH expression reappeared in ovaries from MSCs group. Original magnification: $100 \times . n=5$. 


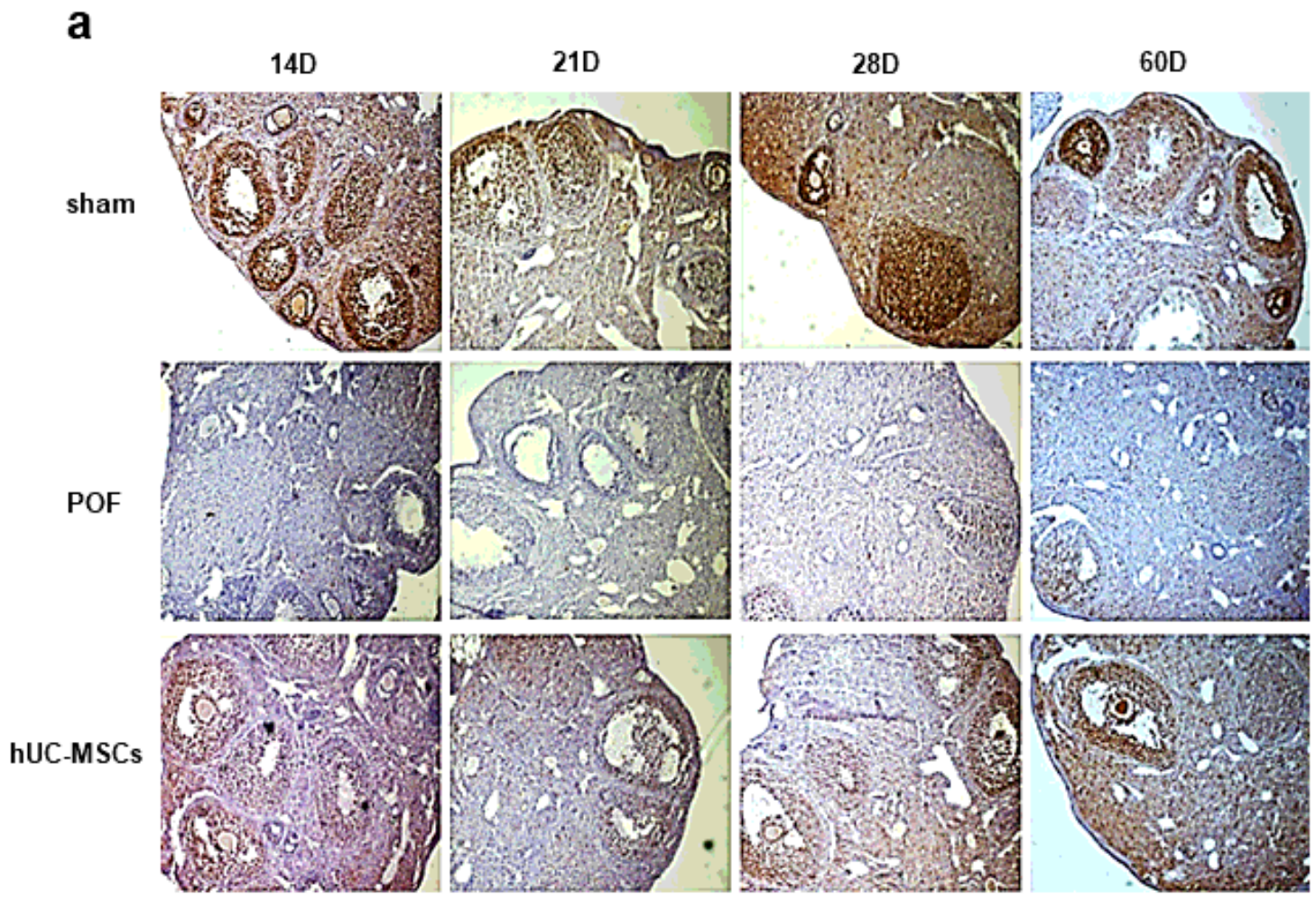

b

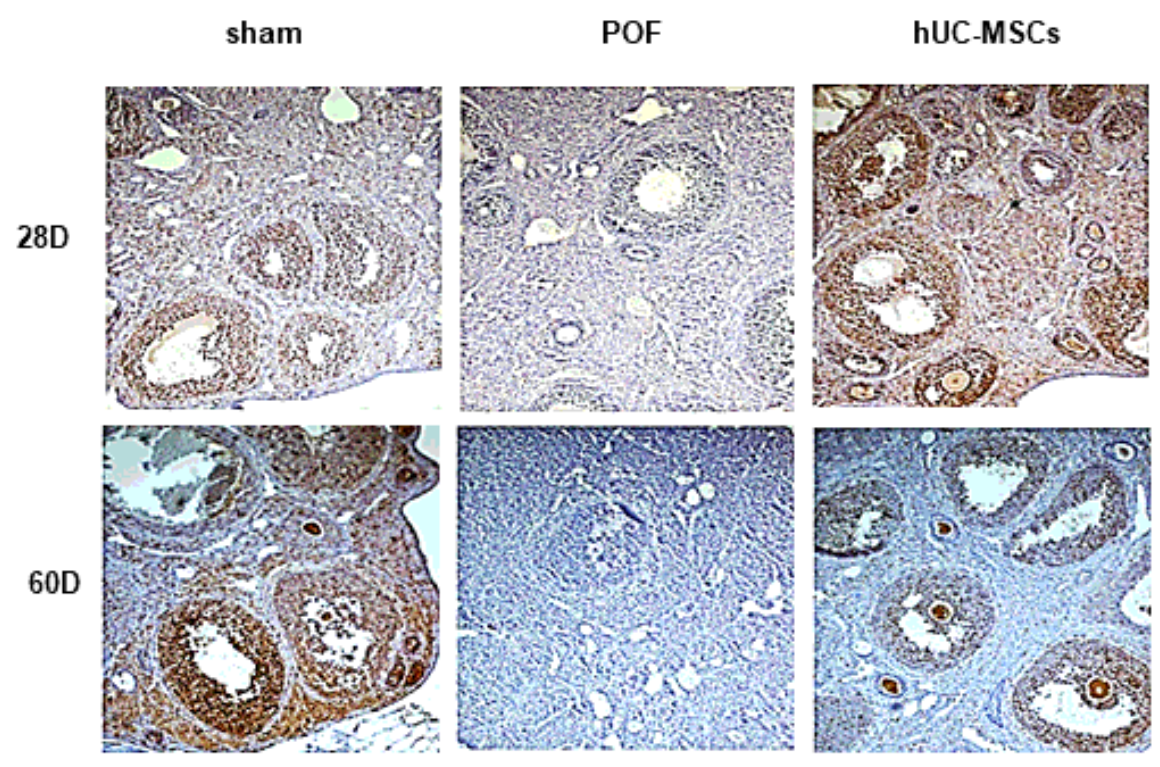

Figure 4

The comparison of ovarian proliferation potential in each group. Immunohistochemistry for KI67 in once intravenous group (a) and the multiple intravenous group (b). Sham mice follicle highly expressed KI67, POF mice follicle lacked KI67 signal, the expression were observed in MSCs group. Original magnification: $400 \times . n=5$. 

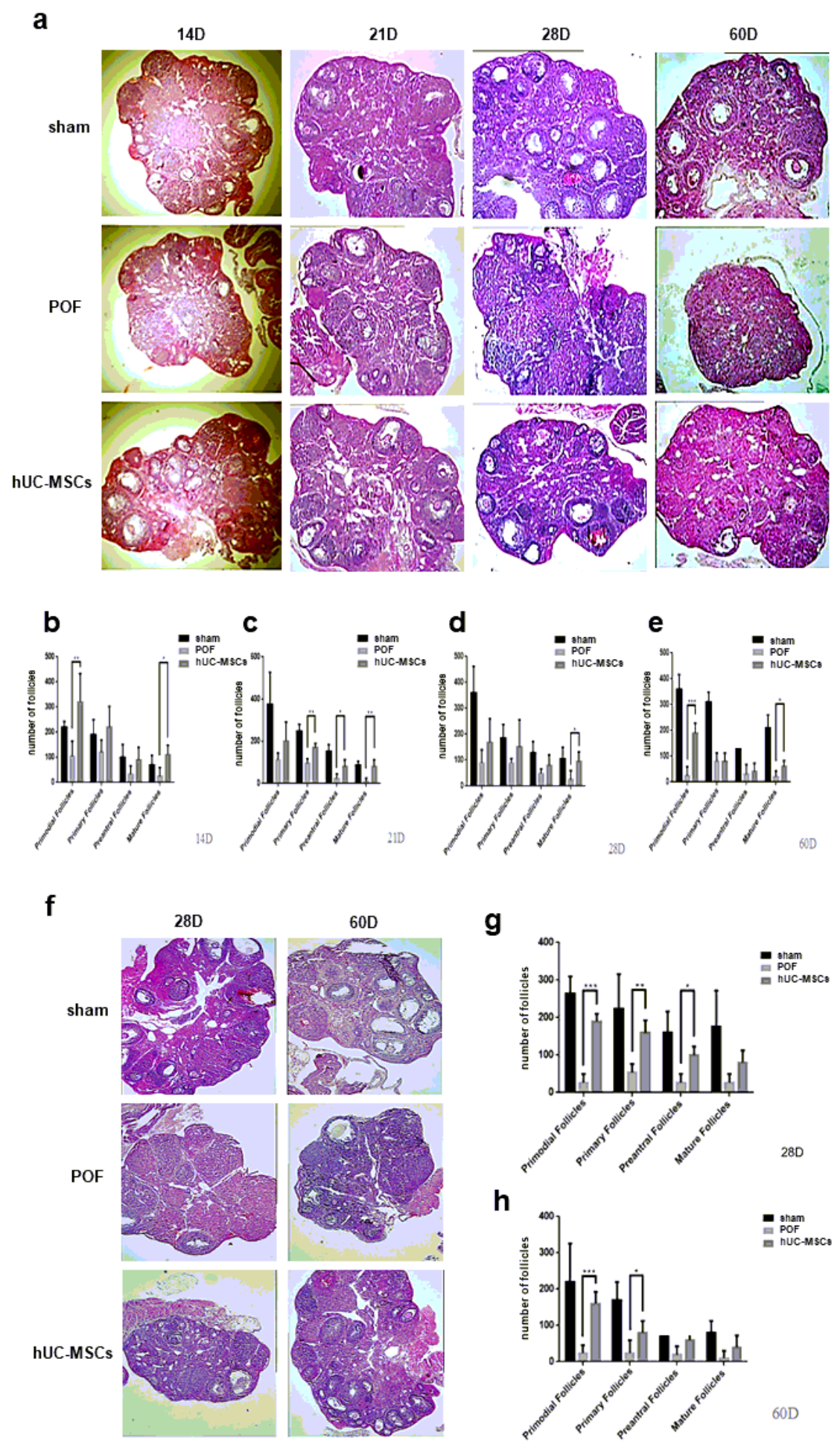

\section{Figure 5}

The effects of hUC-MSC transplantation on ovarian morphology and follicular development in the POF mouse. (a) Representative H\&E micrographs of ovary sections from the once intravenous group over 60 days showing all stages of follicles in Sham group, stroma, and atretic primordial or primary follicles in POF group, primordial as well as primary and large antral follicles in MSCs group. $n=5$. Original magnification: 100x. (b) Follicle counts at all stages on the 14th day. $n=5$. (c) Follicle counts at all stages 
on the 21th day. $n=5$. (d) Follicle counts at all stages on the 28th day. $n=5$. (e) Follicle counts at all stages on the 60th day. $n=5$. (f) Ovarian sections of the multiple intravenous injection group. Original magnification: $100 \times . n=5$. (g) Morphological follicle count of mouse ovaries, the follicle counts at all stages on the 28th day. $n=5$. (h) Morphological follicle count of mouse ovaries, the follicle counts at all stages on the 60th day. $n=5 .{ }^{*} P<0.05 ; * \star P<0.01 ; * \star * P<0.001$.

a

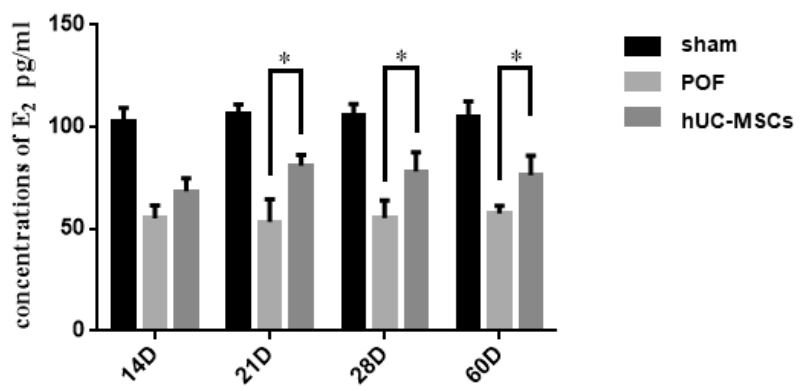

b

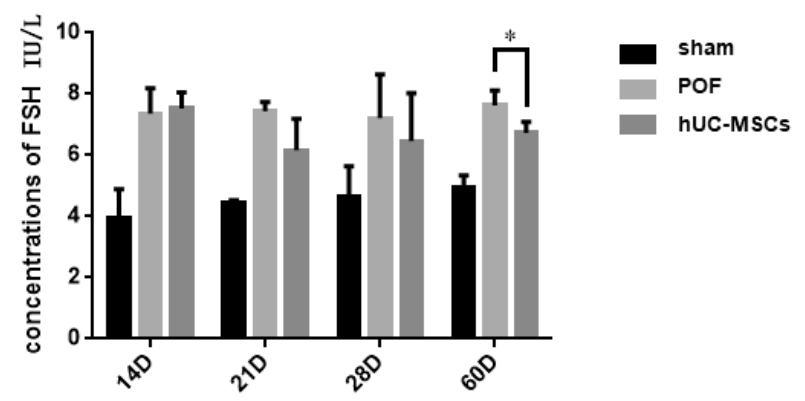

C

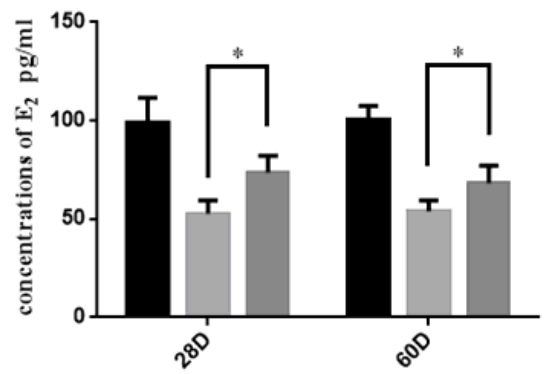

d

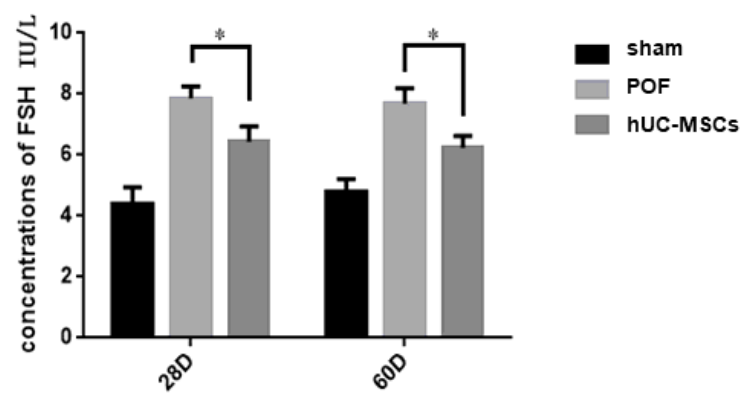

\section{Figure 6}

The effect of hUC-MSCs on the endocrine function of POF mice. (a) The hormone levels of E2 from the once intravenous group and the multiple intravenous group. Comparing the POF and MSCs group, the level of E2 had a significant increase at 21, 28, 60 days post-induction. $n=5$. (b) The level of FSH from the once intravenous group and the multiple intravenous group. It had an obvious difference at 60D. $n=5$. (c) In the multiple group, the levels of E2 were significant differences at 28,60 days post-induction. $n=5$. (d) In the multiple group, the levels of FSH were significant differences at 28,60 days post-induction. $n=5$, ${ }^{*} \mathrm{P}<0.05$. 
a
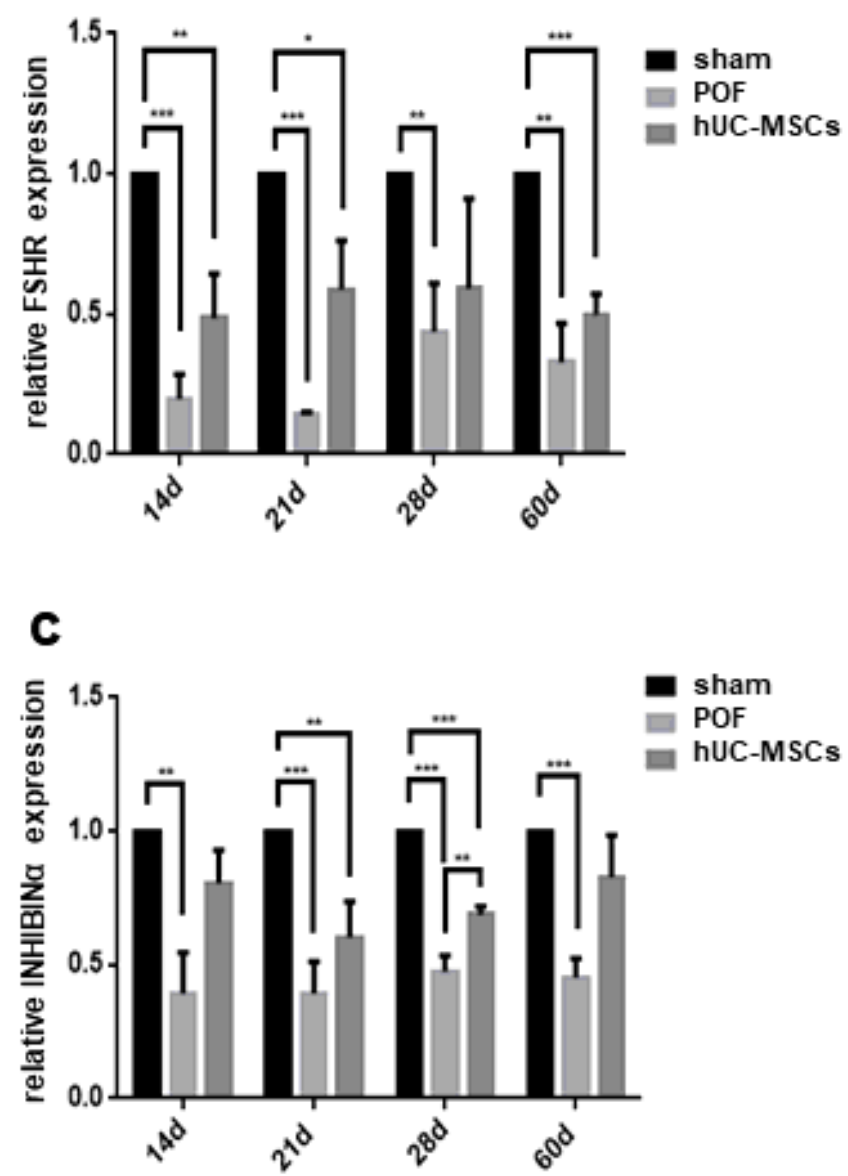

e

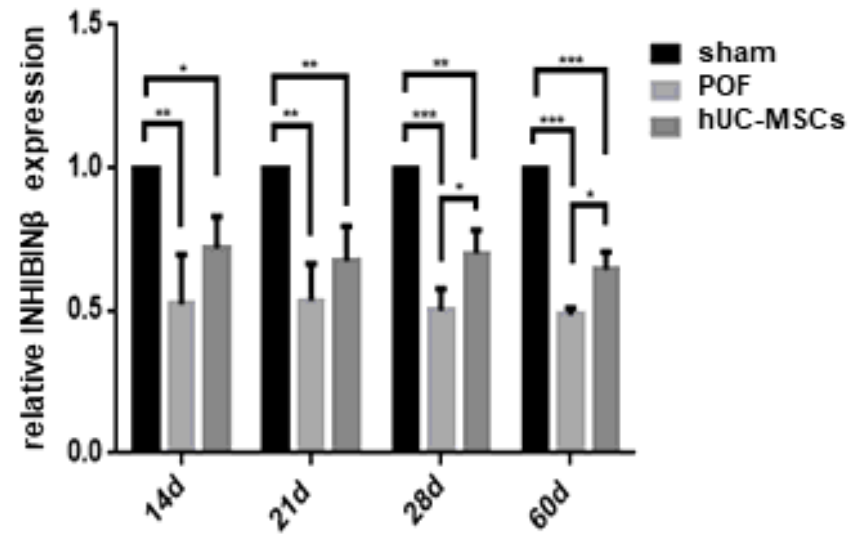

b
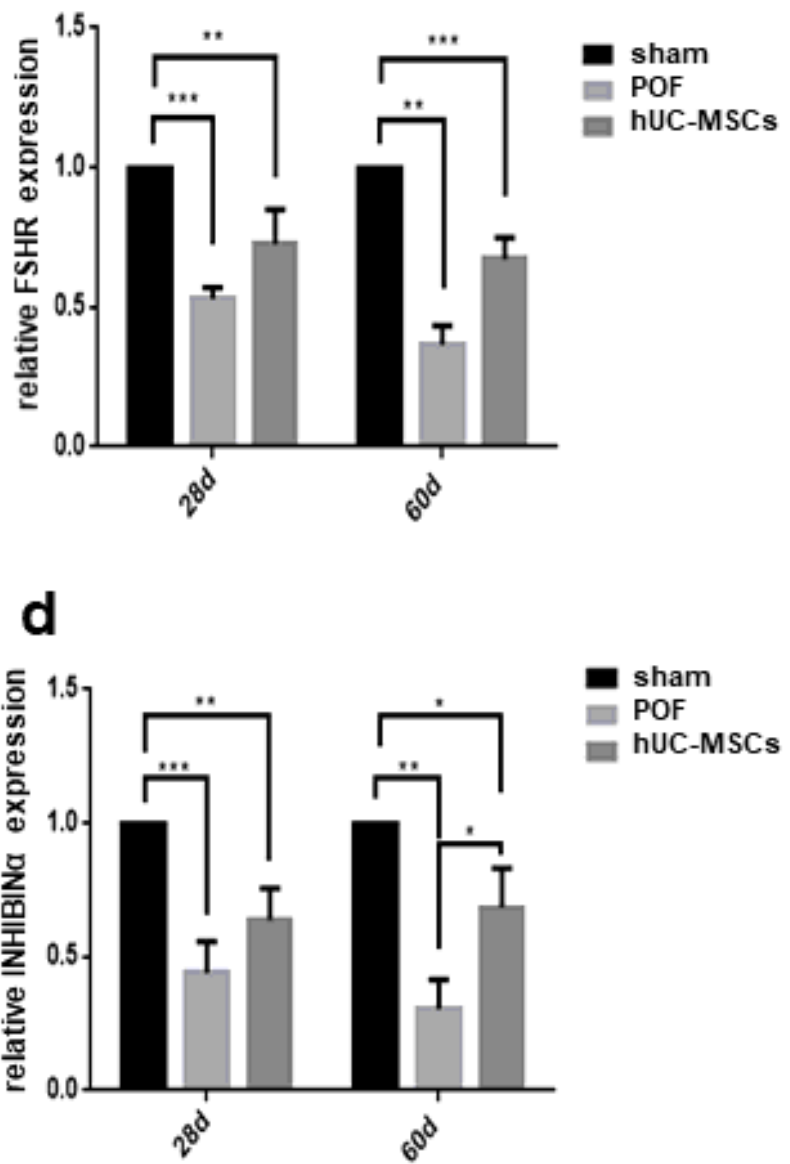

$\mathbf{f}$

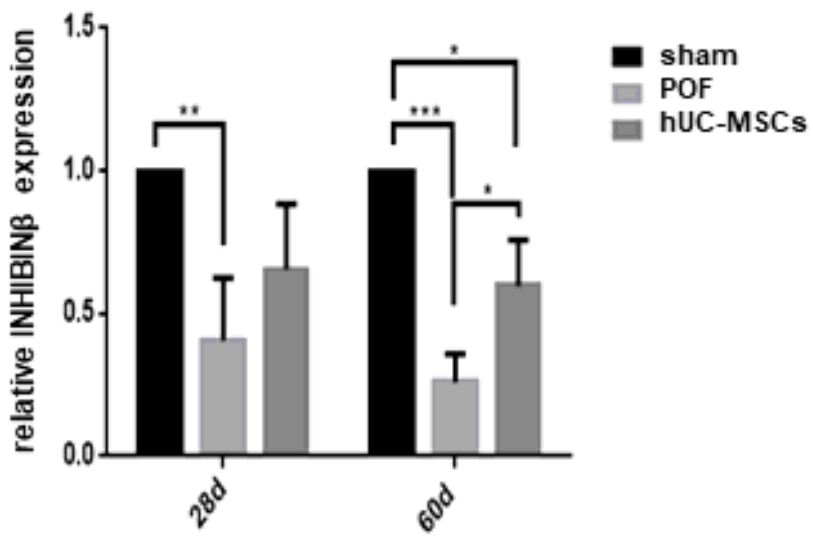

Figure 7

Effect of hUC-MSCs on the ovarian gene expression of POF mice. (a) Expression of FSHR in mouse ovary in single injection of hUC-MSCs group. $n=5$. (b) Expression of FSHR in mouse ovary in the hUC-MSCs group injected multiple times. $n=5$. (c) Expression of INHIBINa in mouse ovary in single injection of hUCMSCs group. $n=5$. (d) Expression of INHIBINa in mouse ovary in the hUC-MSCs group injected multiple times. $n=5$. (e) Expression of INHIBIN $\beta$ in mouse ovary in single injection of hUC-MSCs group. $n=5$. (f) 
Expression of INHIBIN $\beta$ in mouse ovary in the hUC-MSCs group injected multiple times. $n=5$. ${ }^{*}<<0.05$; $\star * P<0.01 ; * \star * P<0.001$.
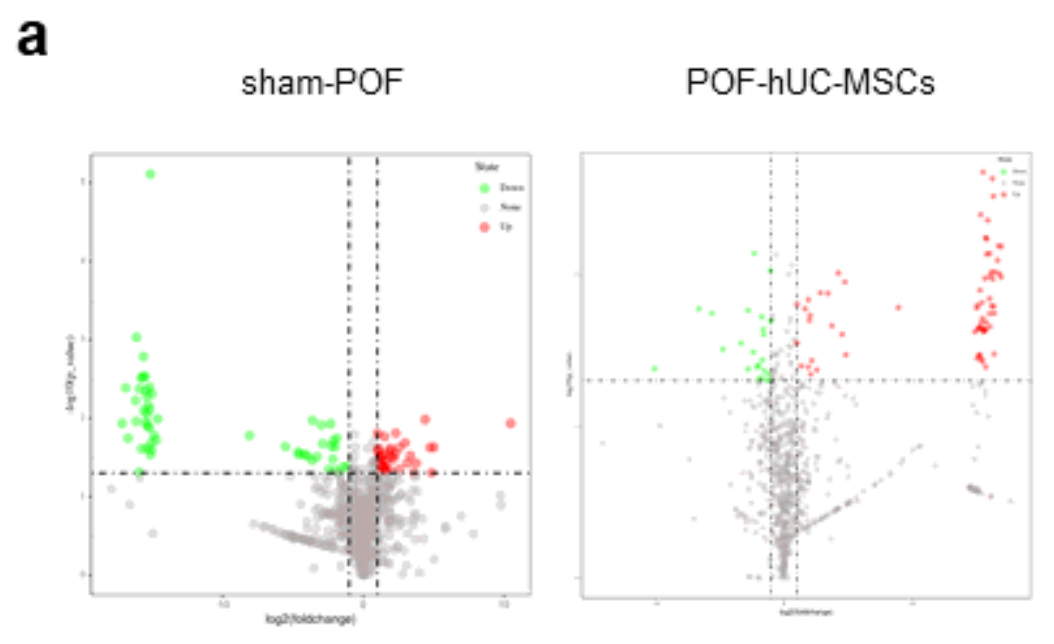

hUC-MSCs-sham

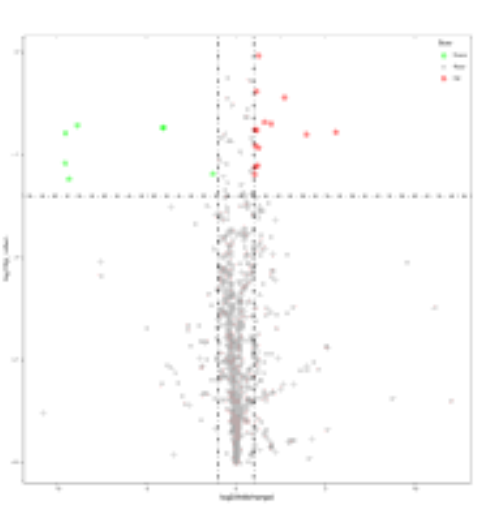

b
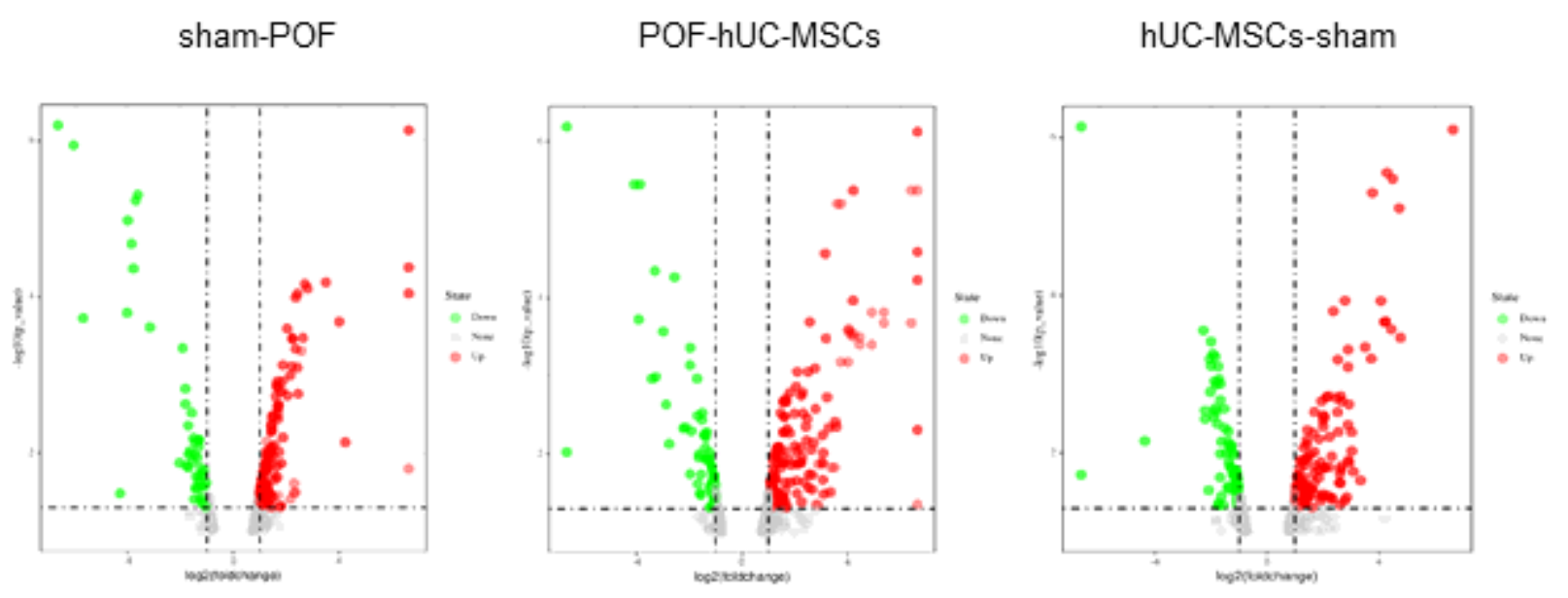

\section{Figure 8}

miRNA chip and mRNA chip detection of mouse ovaries. (a) Volcano map to detect differentially expressed miRNAs between different treatment groups. (b) Volcano map analysis of the mRNA chip.

\section{Supplementary Files}

This is a list of supplementary files associated with this preprint. Click to download.

- 887702323.jpg 